\title{
A EXPERIÊNCIA DO MINTER EM EDUCAÇÃO UFG/IFMT
}

Nádia Cuiabano Kunze ${ }^{1}$

\section{Resumo}

Este texto aborda o Mestrado Interinstitucional em Educação realizado pelo Programa de Pós-Graduação em Educação da Faculdade de Educação da Universidade Federal de Goiás (Instituição Promotora) em parceria com o Instituto Federal de Educação, Ciência e Tecnologia de Mato Grosso (Instituição Receptora). O objetivo deste relato é descrever: a) o processo de formação do intercâmbio estabelecido entre as referidas instituiçóes de ensino para a oferta dessa modalidade de curso de pós-graduação stricto sensu; b) a elaboração do projeto do curso; c) a sua execução; e d) os seus resultados e contribuições. Os procedimentos metodológicos adotados para o alcance desses objetivos foram os da pesquisa documental, que arrolou e analisou os variados documentos institucionais e aqueles referentes ao curso, produzidos durante as suas fases de concepção e realização. Em efeito, destaca-se que o Minter em Educação UFG/ IFMT foi proposto pelas instituiçóes parceiras no âmbito do Edital n. 23/2014 da CAPES que incentivou, selecionou e aprovou projetos de cursos de mestrados e doutorados interinstitucionais, visando fomentar a formação de mestres e doutores atuantes nos diferentes níveis de ensino. Realizado no período de 2015/2 a 2018/1, este curso titulou quinze mestres em educaçáo pertencentes ao quadro de servidores docentes e técnicos administrativos em educação de oito campi do IFMT e da sua reitoria. As dissertaçóes que produziram versam sobre relevantes temas educacionais relacionados ao contexto educativo de pertencimento, o que evidencia a preocupação deles com as questóes educativas do cotidiano.

Palavras-chave: Minter em Educação. Pós-graduação stricto sensu. Intercâmbio UFG-IFMT.

1 Doutora em Educação pela Universidade de São Paulo (USP), coordenadora de Pós-Graduação do Instituto Federal de Educação, Ciência e Tecnologia de Mato Grosso (IFMT), Campus Cuiabá - Octayde Jorge da Silva. E-mail: nadia.kunze@cba.ifmt.edu.br 


\section{Introdução}

O Instituto Federal de Educação, Ciência e Tecnologia de Mato Grosso (IFMT) tem a sua origem na Lei n. 11.892, de 29 de dezembro de 2008, que instituiu a Rede Federal de Educação Profissional, Científica e Tecnológica do Ministério da Educação (RFEPCT/MEC), no âmbito da implementação da expansão da Educação Profissional (EP), promovida pelo governo do presidente Luiz Inácio Lula da Silva.

Enquanto autarquia federal vinculada ao MEC, o IFMT estruturou-se como uma instituição educativa multicampi $i^{2}$ e pluricurricular ${ }^{3}$, detentora de autonomia administrativa, patrimonial, financeira, didático-pedagógica e disciplinar.

O seu quadro de funcionários se constituiu pela inserção e reenquadramento dos servidores efetivos das instituiçóes originárias (CEFETMT, CEFET-Cuiabá, EAFC e UNEDs) e pelas nomeaçóes dos servidores aprovados nos diversos concursos públicos realizados para o provimento dos seus cargos.

Desse modo, se formou um expressivo corpo de profissionais da educação, composto por docentes (professores do ensino básico, técnico e tecnológico - EBTTs) e Técnicos Administrativos em Educação (TAEs) de nível superior (pedagogos, técnicos em assuntos educacionais, psicólogos, assistentes sociais, arquivistas, administradores, bibliotecários-documentalistas, entre outros) e de nível médio (auxiliares em assuntos educacionais, assistentes de alunos, assistentes em administração, técnicos de laboratório, entre outros), atuantes nos campi do IFMT localizados nas microrregióes do estado de Mato Grosso.

2 Inicialmente, compôs-se da integração do Centro Federal de Educação Tecnológica de Mato Grosso (CEFET-MT), do Centro Federal de Educação Tecnológica de Cuiabá (CEFET-Cuiabá), da Escola Agrotécnica Federal de Cáceres (EAFC) e das Unidades de Ensino Descentralizadas (UNEDs) das cidades de Cuiabá (Bela Vista), criada na primeira fase da expansão da EP; Barra do Garças, Campo Novo do Parecis, Confresa, Juína, Pontes e Lacerda e Rondonópolis, criadas na segunda fase da expansão da EP, que foram transformadas em campi. Posteriormente, na terceira fase de expansáo da EP, foram criados outros campi (Alta Floresta, Várzea Grande, Primavera do Leste, Sorriso), campi avançados (Diamantino, Lucas do Rio Verde, Sinop, Tangará da Serra, Guarantá do Norte) e núcleos avançados (Campo Verde, Poconé, Sapezal, Jauru, Jaciara).

3 Especializado a ofertar, regularmente, os cursos de formação inicial e continuada (FIC) ou Qualificação Profissional, cursos técnicos (integrados, concomitantes e subsequentes ao Ensino Médio regular e do Programa Nacional de Integração da Educação Profissional com a Educação Básica na Modalidade de Educação de Jovens e Adultos - PROEJA), cursos superiores de graduação (tecnólogos, licenciaturas e bacharelados) e de pós-graduação (lato sensu/especialização e stricto sensu/mestrado e doutorado). 
De acordo com a área de formação, específica ou afim, aos docentes delegaram-se as atividades de ensino presencial ou à distância (EAD e Universidade Aberta do Brasil - UAB), nos cursos de FIC ${ }^{4}$, de formação profissional técnica de nível médio (integrado, subsequente, concomitante ou do PROEJA), de formação superior de graduação em tecnologia, licenciatura e bacharelado e de pós-graduação lato sensu (especialização) e stricto sensu (mestrado), bem como as práticas de pesquisa e de extensão.

Aos TAEs, por sua vez, também considerando a área de formação específica ou afim, incumbiram-se as atividades gerais de planejamento, organização, execução e avaliação das açóes inerentes ao apoio técnico-administrativo ao ensino, à pesquisa e à extensão, de modo que a estas práticas educativas imprescindíveis se assegurassem a efetividade e o êxito no ambiente institucional.

Desse conjunto de professores do EBTT e dos TAEs com nível superior, graduados em cursos de tecnologias, licenciaturas ou bacharelados das diversas áreas do conhecimento, somente alguns poucos possuíam a titulação de mestre ou de doutor. Até o ano de 2013, do total dos 755 professores do IFMT, 16,02\% eram doutores, 46,89\% mestres, 31,12\% especialistas e $5,96 \%$ graduados.

A respeito dos seus TAEs, do total de 579 , somente $0,34 \%$ eram doutores, $5,18 \%$ mestres, $40,24 \%$ especialistas, $26,08 \%$ graduados e $28,15 \%$ não graduados (UFG; IFMT, 2014). Esses dados indicavam, portanto, que o IFMT possuía uma demanda significativa de 37,08\% de docentes e de $66,32 \%$ de TAEs a serem capacitados em nível de pós-graduação stricto sensu, especificamente, em curso de mestrado.

Considerando que no seu primeiro planejamento estratégico, denominado Plano de Desenvolvimento Institucional (PDI), para execução no quinquênio 2009-2014, o IFMT havia elaborado as diretrizes e açóes para a capacitação, qualificação e formação continuada de seus servidores, especialmente em nível de pós-graduação, a busca de parcerias com renomadas Instituiçóes de Ensino Superior (IES) para a realização de Mestrados interinstitucionais (Minters), voltados ao atendimento daquela demanda existente, foi desencadeada vigorosamente (IFMT, 2009).

A ênfase à oferta dessa modalidade de mestrado se justificava pela possibilidade de se proporcionar, com significativa economia ao orçamento institucional e ao erário público, a formação continuada a um maior número

4 Também referidos como cursos de qualificação profissional. 
de servidores no próprio local de trabalho e num mesmo período, sem a necessidade de licenciá-los por um tempo e de substituí-los por outros profissionais contratados temporariamente para esse fim ${ }^{5}$.

Assim, além da execução de alguns Minters em outras áreas do conhecimento ${ }^{6}$, o IFMT buscou oferecer um Minter em Educação, com o intuito de oportunizar um processo formativo de docentes e pesquisadores capazes de compreender o quadro educacional brasileiro, o fenômeno educacional no contexto mais amplo, a problemática educacional na sua complexidade, totalidade e historicidade; de desenvolver pesquisas sobre temas relativos à educação, ao ensino - abrangendo suas políticas, sistemas, níveis e modalidades, entre outros - e às múltiplas esferas sociais em que se fazem presentes; de produzir conhecimentos promotores de práticas educativas inovadoras, formulaçóes teórico-práticas subsidiadoras de açóes educativas consistentes; de intervir no campo da docência, da pesquisa e da gestão pública em todos os níveis de educação, incluindo os ambientes não formais; enfim, de elaborar uma reflexão crítica sobre seu campo de atuação e a necessária interpretação da realidade.

Por intermédio da sua Pró-Reitoria de Pesquisa e Inovação (PROPES) e Diretoria de Pós-Graduação (DPG), o IFMT passou a realizar os contatos ${ }^{7}$ com as IES detentoras de Programa de Pós-Graduação em Educação (PPGE) promotor de Mestrado em Educação com boa conceituação na avaliação da Coordenação de Aperfeiçoamento de Pessoal de Nível Superior (CAPES), para o estabelecimento de um intercâmbio e proposição de um Minter.

Essa ação se intensificou um pouco mais quando a CAPES lançou o Edital n. 23/2014, publicado no Diário Oficial da União (DOU) em 28 de abril de 2014, que fomentou a submissão de "Novos projetos de mestrado e doutorado interinstitucionais, MINTER/DINTER nacionais e internacionais” por parte das instituiçóes públicas e privadas de ensino e pesquisa com reconhecida oferta de pós-graduação stricto sensu, para fins de seleção e autorização.

5 Apesar desse destaque aos Minters, ocorreram, também, a autorização de licença capacitação aos servidores para formação continuada em Programas de Pós-Graduação (PPGs) de IES nacionais ou internacionais, a celebração de convênios com IES para a formação de turmas especiais de seus mestrados para o IFMT, a oferta de alguns cursos próprios de especialização e do Curso de Mestrado em Tecnologia de Alimentos, iniciado em 2012.

6 Minter em Engenharia Elétrica com a Universidade de Brasília (UnB) entre 2010 e 2012 e Minter em Ciência Política com a Universidade Federal de Pernambuco (UFPE) entre 2011 e 2013 (KUNZE, 2013).

7 Promovidos pelos gestores responsáveis na época (Prof. Dr. Antônio Carlos Vilanova - PROPES e Prof. Dr. Xisto Rodrigues de Souza - DPG). 
Dentre os diálogos realizados com diversas IES, o mais frutífero se deu com a Universidade Federal de Goiás (UFG), por meio da Coordenação do PPGE ${ }^{8}$ da sua Faculdade de Educação (FE), o que favoreceu a definição da parceria e, consequentemente, a execução dos procedimentos legais e burocráticos para fins de sua oficialização e concretização, conforme se demonstrará a seguir.

\section{0 estabelecimento do intercâmbio entre o IFMT e a UFG para a oferta do Minter em Educação}

A decisão do IFMT de se consorciar à UFG para a realização de um Minter em Educação se baseou na reconhecida qualidade do PPGE/FE/UFG com seu alto nível de desempenho, traduzido na nota cinco atribuída pela CAPES ao seu mestrado e doutorado, nas duas avaliações trienais (2007 a 2009 e 2010 a 2012) anteriores.

Ademais, considerou a sua plena consolidação e experiência acumulada com a execução de Minters ${ }^{9}$ e de Dinters ${ }^{10}$ em épocas antecedentes, bem como a sua localização geográfica, favorecedora do compromisso em atuar sistematicamente na formaçãao de mestres e doutores em educação na região Centro-Oeste e, ainda, as suas condiçóes e disponibilidade em dar continuidade à cooperaçáo interinstitucional, na condição de instituição promotora do curso.

Por outro lado, a decisão do PPGE/FE/UFG de estabelecer o intercâmbio com o IFMT se baseou nos resultados que obteve com realizaçáo de uma avaliação que consistiu no preenchimento, em data estipulada, de um formulário elaborado por uma comissão composta por alguns de seus professores para esse fim. Além do IFMT, outras dez instituiçóes, situadas nos estados de Goiás, Paraíba, Ceará, Minas Gerais, Espírito Santo, Rondônia e Pernambuco, participaram da avaliação, pois, igualmente, buscavam parceria para submissão de projeto no citado edital da Capes.

Os critérios adotados pelo PPGE/FE/UFG para seleção da instituição receptora do Minter expressaram os princípios e as orientaçóes decorrentes da sua

8 Sob a responsabilidade, na época, do Prof. Dr. Wanderson Ferreira Alves.

9 O primeiro Minter em Educação foi com a Universidade Estadual do Tocantins (UNITINS), de 2000 a 2003, e o segundo com a Universidade de Rio Verde/GO (UniRV), de 2006 a 2008 (UFG; IFMT, 2014).

10 O primeiro Dinter em Educação foi com a Universidade Federal do Tocantins (UFT), de 2007 a 2011, e o segundo com o Campus Jataí do Instituto Federal de Educação, Ciência e Tecnologia de Goiás (IFG) e os Campi Jataí e Catalão da própria UFG, de 2010 a 2014 (UFG; IFMT, 2014). 
experiência adquirida anteriormente na oferta dessa modalidade de mestrado. Atendendo, incialmente, ao prioritário, ou seja, o de ser instituição pública de ensino e de pesquisa, o IFMT respondeu aos demais da seguinte forma:

a) apresentou uma estimativa de relaçáo entre a quantidade de candidatos e o número de vagas previstas (no caso, vinte) além da mínima de 3/1 exigida, com a de 8,6/1. Para isso, efetuou um levantamento diagnóstico junto ao seu quadro geral de funcionários para averiguar se havia o interesse de alguns deles em cursar um Minter em Educação com a UFG e obteve a devolutiva positiva total de cento e setenta e dois interessados, sendo cento e seis TAEs e sessenta e seis docentes, cuja maioria deles com formação em cursos de licenciaturas e áreas correlatas;

b) apresentou termo de compromisso de garantia de licença de, no mínimo, seis meses aos seus servidores em formação no Minter para se deslocarem até a sede do curso, na cidade de Goiânia/GO, para realizarem o estágio obrigatório;

c) apresentou uma perspectiva de financiamento do Minter com recursos próprios e de outras formas de apoio aos docentes e alunos e; por fim;

d) indicou uma coordenadora ${ }^{11}$ responsável pelo Minter localmente, durante todo o seu período de execução.

Depois dessa fase que estabeleceu o vínculo entre as duas instituiçôes e a indicação da coordenadora ${ }^{12}$ responsável pelo Minter no âmbito do PPGE/ FE/UFG, iniciou-se o processo de elaboração conjunta ${ }^{13}$ do Projeto de Mestrado Interinstitucional em Educação do PPGE/FE/UFG/IFMT, o qual será referenciado na seção que segue.

\section{Projeto do Minter em Educação PPGE/FE/UFG/IFMT}

A proposta do Minter em Educação foi elaborada pelo PPGE/FE/UFG, na condição de instituição promotora, e o IFMT, na condição de instituição receptora, em conformidade com as diretrizes estabelecidas no Edital/CAPES n. 23/2014, que, em termos gerais, orientaram a construção e submissão de Projetos Minters e Dinters voltados à viabilização da capacitação de docentes

11 Dra. Nádia Cuiabano Kunze.

12 Inicialmente, foi indicada a Profa. Dra. Sandra Valéria Limonta que, quando se tornou a coordenadora do PPGE/FE/UFG, em 2015, foi substituída pela Profa. Dra. Lúcia Maria de Assis.

13 Coordenadoras locais, pró-reitor de Pesquisa e Inovação do IFMT e coordenador do PPGE/FE/ UFG, sob a orientação da Profa. Dra. Marilia Gouvea de Miranda, do PPGE/FE/UFG. 
para os diferentes níveis de ensino e a formação de mestres e doutores com o mesmo padrão de qualidade existente no programa promotor.

No projeto enviado à avaliação da CAPES em 17 de junho de 2014, por meio de submissão eletrônica no Sistema Integrado CAPES (SICAPES) ${ }^{\mathbf{1 4}}$, o Minter em Educação PPGE/FE/UFG/IFMT foi definido como uma turma “especial” do Curso de Mestrado Acadêmico do PPGE/FE/UFG ofertada fora da sede, por tempo delimitado.

Caracterizado, então, como uma turma única de alunos, conduzida pela instituição promotora nas dependências da instituição receptora por um determinado período, propôs os objetivos de:

a) viabilizar a formação de mestres em educação do quadro de professores e técnicos administrativos em educação do IFMT, tendo em vista elevar a qualificação do corpo docente da instituição;

b) contribuir com a nucleação e o fortalecimento de grupos de pesquisa na área de educação no âmbito do IFMT;

c) contribuir com o fortalecimento e estabelecimento de condições para a criação de novos cursos de pós-graduação no IFMT, sobretudo na área de educação;

d) contribuir com a produção de conhecimento de temas de pesquisas que respondam a necessidades do estado de Mato Grosso, ampliando o comprometimento institucional com o desenvolvimento da região;

e) contribuir para o surgimento, no âmbito do IFMT, de novas vocaçóes para pesquisa, mediante o incentivo à participação de bolsistas de iniciação científica;

f) contribuir para o estabelecimento de parcerias duradouras entre o PPGE/FE/UFG e os grupos de pesquisa no IFMT. (UFG; IFMT, 2014, p. 6).

Para o atendimento desses propósitos, a sua estruturação acadêmico-curricular foi proposta nos moldes do Mestrado regular ofertado pelo PPGE/FE/UFG, com as mesmas orientaçóes legais oficiais, de

14 Via aplicativo para Projetos Minter/Dinter, disponível na página eletrônica: http://www.capes.gov. br/avaliacao/Projetos:Minter\%20e/ou\%20Dinter 
modo a se evitar que as suas especificidades pudessem se constituir em fatores de sua desqualificação.

Assim, a sua estrutura curricular compôs-se de disciplinas ${ }^{15}$ obrigatórias e eletivas, e de atividades complementares, articuladas às cinco Linhas de Pesquisa (LP) ${ }^{16}$ do Programa de origem. Definiu-se, então, que as disciplinas obrigatórias seriam ofertadas aos alunos no local de trabalho, ou seja, no IFMT, e as eletivas na UFG, devendo ser cursadas por eles durante a época da realização do Estágio Obrigatório, mediante a anuência do(a) orientador(a).

Esse período de permanência obrigatória dos alunos na sede do PPGE/ FE/UFG, no decurso de um semestre, foi previsto com a finalidade de favorecer-lhes: o cumprimento dos créditos exigidos em disciplinas e para a conclusão do curso $^{17}$; a dedicação integral a elas, aos estudos e à pesquisa; a realização das primeiras atividades de orientação; a convivência com os docentes do Programa e com os outros alunos das turmas do Mestrado regular; a participação nos grupos de pesquisas das suas LPs de modo a ampliarem seus interesses e perspectivas de reflexão e atuação sistemática na área, bem como estabelecerem e consolidarem vínculos entre pesquisadores; a participação nos eventos (seminários, simpósios, congressos, etc.) e nas atividades extracurriculares (reunióes de estudos, de grêmio estudantil, centro acadêmico, etc.) na FE/UFG; a utilização da infraestrutura da UFG (bibliotecas, salas de estudos, laboratórios, arquivos, auditórios, teatros, etc.) para o desenvolvimento de suas pesquisas e, também, para o seu lazer (UFG; IFMT, 2014).

Quanto ao seu quadro docente, prognosticou-se o engajamento de vinte e dois professores do PPGE/FE/UFG credenciados no Mestrado regular, vinculados às LPs e regentes de disciplinas, para ofertarem vagas de orientação.

Para a ocorrência de orientações profícuas recomendou-se a elaboração de um planejamento básico com a descrição objetiva das relaçôes entre orientador(a) e orientando(a), bem como a realização de reuniôes presenciais intensivas no período de estágio obrigatório e, posteriormente, de encontros frequentes no IFMT ou na FE/UFG, dependendo da programação definida

15 Cada uma correspondente a oito créditos e com carga horária total de 120 horas, sendo 60 horas presenciais.

16 LP I - Educação, Trabalho e Movimentos Sociais; LP II - Estado, Políticas e História da Educação; LP III - Cultura e Processos Educacionais; LP IV - Formação, Profissionalização Docente e Trabalho Educativo; e LP V - Fundamentos dos Processos Educativos.

17 Tal como no mestrado regular, exigiu-se no Minter a integralização de 32 créditos, sendo 16 atribuídos em disciplinas e 16 à defesa e aprovação da dissertação. 
e, ainda, a orientação à distância com a utilização de recursos tecnológicos (Skype, videoconferência, mensagens eletrônicas, etc.).

No que diz respeito ao cronograma de execução, o prazo previsto para conclusão do Minter em Educação PPGE/FE/UFG/IFMT foi de, no mínimo, dezoito meses e, no máximo, de vinte e quatro meses, contados a partir da matrícula inicial. No entanto, se assegurou ao aluno a possibilidade de requerer a prorrogaçáo por até seis meses, com a concordância do orientador, antes de se completarem os vinte e quatro meses.

Considerando esses prazos estabelecidos, a organização dos semestres estimou-se com as seguintes etapas:

- Primeiro semestre - oferta das disciplinas obrigatórias no IFMT;

- Segundo semestre - oferta das disciplinas eletivas, Estágio Obrigatório, desenvolvimento da pesquisa e orientação de dissertação na UFG;

- Terceiro semestre - desenvolvimento da pesquisa e orientação de dissertação no IFMT e/ou na UFG;

- Quarto semestre - desenvolvimento da pesquisa e orientação de dissertação no IFMT e/ou na UFG. Período limite para realização do Exame de Qualificação e Defesa da dissertação em prazo regulamentar (24 meses);

- Quinto semestre - desenvolvimento da pesquisa e orientação de dissertação no IFMT e/ou na UFG. Período limite para realização do Exame de Qualificação e Defesa da dissertação em prazo de prorrogaçáo (30 meses). (UFG; IFMT, 2014).

Por fim, para o preenchimento das vagas disponibilizadas ao IFMT, definiu-se a realização do processo de seleção dos servidores candidatos com os mesmos critérios e procedimentos adotados nos processos seletivos de ingresso dos alunos do Mestrado regular do PPGE/FE/UFG, firmados anualmente por meio de editais. A diferença residiu na inclusão de uma etapa anterior à publicação do edital, para a divulgação e esclarecimentos, e na possibilidade da realização de algumas fases do processo seletivo no próprio IFMT, conforme descrito na seção seguinte. 


\section{0 processo seletivo do Minter em Educação PPGE/FE/UFG/IFMT}

O Projeto do Minter em Educação PPGE/FE/UFG/IFMT, submetido ao Edital/CAPES n. 23/2014, teve seu parecer de recomendação de aprovação expedido em 10 de fevereiro de 2015, ou seja, oito meses depois da sua submissão. Com isso, a coordenação do PPGE/FE/UFG e a da DPG/ PROPES/IFMT, juntamente com as coordenaçóes locais do Minter, da UFG e do IFMT, iniciaram imediatamente os procedimentos para a realização do processo seletivo logo no primeiro semestre de 2015 para que o curso pudesse começar no semestre seguinte.

A primeira etapa consistiu na elaboração da normativa regulamentadora da seleção, ou seja, do Edital n. 02/2015, de $1^{\circ}$ de abril e 2015, que instruiu os procedimentos de inscrição e avaliação dos candidatos e de matrícula dos aprovados.

Em termos gerais, o documento indicou: a oferta de vinte vagas distribuídas entre as linhas de pesquisa, conforme indica a tabela 1; o requisito de habilitação à inscrição, ou seja, de o candidato ser servidor efetivo do IFMT, docente ou TAE, e portador de título de graduação; o prazo de inscrição (15.04 a 08.05.2015); os documentos exigidos; os tipos de avaliaçóes, suas notas mínimas de classificação e aprovação; o cálculo de média geral; o período da matrícula (06 e 07.08.2015) e o cronograma do processo seletivo (UFG, 2015).

A etapa seguinte consistiu na realizaçáo de uma palestra no dia da abertura das inscrições da seleção, proferida pelo coordenador do PPGE/FE/UFG no auditório da sede da Reitoria do IFMT, na qual foram apresentados os informes sobre o Minter e o Programa executor e sanadas as dúvidas dos servidores presentes. Com o objetivo de garantir uma ampla divulgação e participação dos servidores nesse evento, a PROPES/IFMT emitiu antecipadamente um convite geral a todos eles, providenciou a transmissão da palestra em tempo real, por videoconferência, a todos os campi, bem como a sua gravação para disponibilização posterior aos interessados.

$\mathrm{Na}$ fase seguinte, em dias diversos (20, 22 e 30.04.2015), a PROPES/ IFMT ofertou naquele mesmo local a "Oficina de Elaboração de Projetos para seletivo do Minter em Educação UFG/IFMT”, ministrada pela coordenadora local do IFMT, que também foi transmitida por videoconferência aos campi, gravada e disponibilizada.

A participação dos servidores nesses eventos, tanto de forma presencial como à distância, foi satisfatória, pois possibilitou-lhes uma preparação ade- 
quada com acompanhamento e, ainda, confirmou a demanda e o interesse apontados naquele levantamento diagnóstico apresentado ao PPGE/FE/ UFG, durante a fase da definição da parceria. Finalizada a etapa das inscriçóes gratuitas efetuadas de modo presencial na PROPES/IFMT e por correio, o coordenador do PPGE/FE/UFG procedeu a homologação delas, in loco, deferindo quarenta e seis e indeferindo duas, do total de quarenta e oito (vinte e seis de TAEs e vinte e dois de docentes). Apesar da ampla divulgação ocorrida e da existência comprovada de expressiva demanda interessada, essa quantidade de inscriçóes efetuadas não correspondeu às expectativas institucionais.

Em seguida, na sede da Reitoria do IFMT, ocorreram sequencialmente as seguintes avaliaçóes:

a) prova escrita sem consulta, de caráter eliminatório, com nota mínima exigida de sete, aplicada pela coordenadora local do Minter da UFG, no dia 19.05.2015, com duração de quatro horas, apresentando questão ${ }^{\mathbf{1 8}}$ sobre tema relacionado à Educação, cuja redação do candidato deveria apresentar a sua capacidade de reflexão e análise, bem como de articulação teórica que demonstrasse diálogo com a área;

b) análise do projeto submetido na inscrição, de caráter eliminatório, com nota mínima exigida de sete, centrada no exame de sua pertinência a uma das linhas de pesquisa do Programa, oferecedora de vaga, consistência teórico-metodológica, e de seus elementos constitutivos (delimitação do tema, definição do problema, justificativa, referencial teórico, metodologia e referências) ${ }^{\mathbf{1 9}}$;

c) exame de suficiência em uma língua estrangeira ${ }^{20}$ inglesa e espanhola, com permissão de uso de dicionário impresso, de caráter eliminatório, com nota mínima exigida de seis, aplicada pela coordenadora local do Minter da UFG, no dia 12.06.2015, com duração de quatro horas, consistindo em tradução e questôes de compreensão de texto científico da área de Educação;

d) exames orais de caráter eliminatório, com nota mínima exigida de sete, aplicados entre os dias 22 e 26.06 .2015 por bancas examinadoras compostas por docentes das linhas de pesquisa ofertadoras de vagas e pela coordenadora

18 Formulada e corrigida no PPGE/FE/UFG pela Comissão do processo seletivo do Minter, composta por alguns docentes do Programa que se vincularam a esse curso.

19 Esta etapa foi realizada no PPGE/FE/UFG entre os dias 2 e 9 de junho de 2015.

20 Formulada e corrigida no PPGE/FE/UFG. 
local do Minter da UFG, versando sobre o conteúdo acadêmico-científico do Projeto de pesquisa e do Currículo Lattes, submetidos na inscrição, somente dos candidatos aprovados nas fases seletivas anteriores.

Ao término de todas essas avaliaçóes, foi divulgado no dia 02.07.2015 o resultado final indicando a classificação ${ }^{21}$ dos candidatos aprovados, por linha de pesquisa, bem como os respectivos orientadores, em ordem alfabética dos nomes.

Dos quarenta e seis servidores submetidos a esse processo seletivo, somente dezesseis deles foram selecionados por terem adquirido a média geral individual acima da nota mínima exigida de sete. Dentre os aprovados, constaram sete docentes ${ }^{22}$ e nove TAEs ${ }^{23}$.

\section{Tabela 1 - Vagas do Minter em Educação PPGE/FE/UFG/IFMT}

\begin{tabular}{l|c|c|c}
\hline Linhas de Pesquisa & $\begin{array}{c}\text { Vagas } \\
\text { ofertadas }\end{array}$ & $\begin{array}{c}\text { Vagas } \\
\text { preenchidas }\end{array}$ & $\begin{array}{c}\text { Vagas não } \\
\text { preenchidas }\end{array}$ \\
\hline $\begin{array}{l}\text { I - Educação, Trabalho e Movimentos } \\
\text { Sociais }\end{array}$ & 03 & 02 & 01 \\
\hline $\begin{array}{l}\text { II - Estado, Políticas e História da } \\
\text { Educação }\end{array}$ & 04 & 04 & 00 \\
\hline III - Cultura e Processos Educacionais & 03 & 03 & 00 \\
\hline $\begin{array}{l}\text { IV - Formação, Profissionalização } \\
\text { Docente e Trabalho Educativo }\end{array}$ & 04 & 03 & 01 \\
\hline $\begin{array}{l}\text { V - Fundamentos dos Processos Edu- } \\
\text { cativos }\end{array}$ & 06 & 04 & 02 \\
\hline \begin{tabular}{l} 
Total \\
\hline
\end{tabular}
\end{tabular}

21 A classificação dos candidatos selecionados se deu com base no cálculo da Média Geral individual (MG), que consistiu na média aritmética das notas obtidas na Prova Escrita (PE), na Análise do Projeto (AP) e no Exame Oral (EO).

22 Três docentes do Campus Cuiabá/Octayde Jorge da Silva, graduados em Letras, Física e Engenharia Sanitária, um docente do Campus Diamantino, graduado em Educação Artística, um docente do Campus Rondonópolis, graduado em Engenharia Industrial Mecânica, um docente do Campus São Vicente da Serra, graduado em Letras, uma docente do Campus Tangará da Serra, graduada em Administração.

23 Um TAE da Reitoria, graduado em Ciências Contábeis, dois TAEs do Campus Barra do Garças, graduados em Psicologia e Ciências Contábeis, uma TAE do Campus Bela Vista, graduada em Química, duas TAEs do Campus Cuiabá/Octayde Jorge da Silva, graduadas em Biologia e Biblioteconomia, uma TAE do Campus Rondonópolis, graduada em Biologia e duas TAEs do Campus Várzea Grande, graduadas em Pedagogia e Serviço Social. 
Das vinte vagas disponibilizadas, quatro não foram preenchidas e, assim, nem todas aquelas ofertadas pelas linhas de pesquisa se efetivaram, conforme esclarece a tabela 1.

Nos dias 6 e 7 de agosto de 2015, na Coordenação Local do MINTER do IFMT, nas dependências da sede da Reitoria, procedeu-se à realização da matrícula ${ }^{24}$ dos dezesseis servidores aprovados que iniciaram, naquele período, o processo de formação no curso, o qual será abordado a seguir.

\section{0 percurso do Minter em Educação PPGE/FE/UFG/IFMT}

O primeiro semestre letivo do Minter se desenvolveu no período de 13.08.2015 a 18.03.2016 no IFMT25, e teve seu início frisado com a aula inaugural intitulada "Educação e Formação Humana", proferida pelo Prof. Dr. Ildeu Moreira Coelho, docente do PPGE/FE/UFG.

Seguindo o calendário letivo do curso, organizado pelas Coordenaçóes locais em conjunto com a Coordenação do Programa, foram ofertadas e ministradas duas disciplinas obrigatórias, a de "Educação Brasileira", ministrada pela Profa. Dra. Diane Valdez e a de "Pesquisa em Educação", ministrada pela Profa. Dra. Marília Gouvea de Miranda, ambas do PPGE/FE/UFG, cujas aulas se concentraram em dois dias da semana (quintas e sextas-feiras), nos turnos matutino e vespertino.

No semestre seguinte, correspondente ao período de 30.03.2016 a 25.07.2016, todos os servidores mestrandos obtiveram a licença integral de suas atividades profissionais na instituição receptora para realizarem o Estágio Obrigatório na instituição promotora.

Essa inserção integral dos alunos na sede do PPFGE/FE/UFG propiciou-lhes o cumprimento dos demais créditos exigidos em disciplinas, posto que puderam se matricular em alguma(s) das que foram ofertadas ${ }^{\mathbf{2 6}}$, naquele

24 Posteriormente, toda a documentação dos servidores matriculados foi transferida para a Secretaria da Coordenação do PPGE/FE/UFG.

$25 \mathrm{Na}$ sede da Reitoria foi disponibilizado o auditório e uma sala de estudos para os encontros.

26 Foram elas: "Corpo na sociedade do Capital”, ministrada pelo Prof. Dr. Tadeu Baptista; "Juventude e Educação", ministrada pela Profa. Dra. Edna Mendonça Oliveira de Queiroz; "Docência e identidade profissional”, ministrada pela Profa. Dra. Nancy Nonato de Lima Alves; "Paulo Freire e a Educaçáo", ministrada pela Profa. Dra. Maria Emília de Castro Rodrigues; "Cultura, Arte e Educação", ministrada pela Profa. Dra. Juliana de Castro Chaves; "A escola nas tramas da educação, da cultura e da política”, ministrada pelo Prof. Dr. José Adelson Cruz; "Estética, educação e imagens da arte”, ministrada pela Profa. Dra. Rita Márcia Furtado; "Formação e profissionalização de professores(as): epistemologias, pesquisas e perspectivas críticas”, ministrada pela Profa. Dra. Ruth Catarina Cerqueira de Souza. 
período, no curso regular. Além disso, favoreceu-lhes as orientaçóes iniciais, a realização das atividades complementares e de pesquisa, a participação nas reunióes dos grupos de pesquisa, nos seminários e congressos, nos ambientes universitários, enfim, na vida acadêmica estudantil.

A partir do terceiro semestre, realizado entre 18.08.2016 e 10.03.2017, os servidores mestrandos retornaram aos seus campi de origem dando prosseguimento à formaçáo continuada em serviço, porém, obtiveram a dispensa integral de suas atribuiçôes funcionais em dois dias da semana (quintas e sextas-feiras), em cumprimento à exigência da instituição promotora à receptora.

Nesse retorno, além de se dedicarem à elaboração dos trabalhos finais (produção textual sob a forma de artigos, ou de relatórios, ou de ensaios críticos, entre outros) das disciplinas cursadas durante o Estágio Obrigatório na FE/UFG, os servidores mestrandos deram continuidade à execução de suas pesquisas efetuando os estudos bibliográficos, coleta dos dados, produção do texto para a qualificação e de artigos científicos.

Constantemente, empreenderam deslocamentos de suas cidades até a de Cuiabá para participarem de reunióes da Coordenação local do Minter no IFMT, bem como até a localidade de Goiânia para as reuniôes de orientação da pesquisa com os orientadores e para os encontros de estudos das linhas/ grupos de pesquisa de vinculação no PPGE/FE/UFG.

Também estiveram presentes em diversos eventos científicos da área, ocorridos na UFG, ou em outras instituiçóes e localidades, na condição de ouvintes e de participantes autores com a apresentação de trabalhos científicos por meio de pôster ou comunicação oral.

No final desse semestre, as Coordenações locais do Minter na UFG e IFMT promoveram, ainda, um encontro intitulado "Seminário de pesquisas do Minter em Educação UFG-IFMT e do Mestrado em Ensino do IFMTUNIC", realizado no Campus Cuiabá - Cel. Octayde Jorge da Silva do IFMT, nos dias 22 e 23 de fevereiro de 2017.

Esse evento científico buscou estabelecer a troca de experiências entre o Minter e o Mestrado em Ensino, que é outro processo de formação em nível de pós-graduação stricto sensu do IFMT, voltado às comunidades interna e externa, efetivado em rede com a Universidade de Cuiabá (UNIC).

Nesse espaço de socialização e divulgação das investigações desenvolvidas no âmbito dos dois mestrados, além da palestra de abertura intitulada "Cenários e perspectivas da pesquisa e da pós-graduação em educação no 
Brasil”, proferida pelo Prof. Dr. João Ferreira de Oliveira, do PPGE/FE/ UFG, ocorreram mesas de diálogos com reflexóes acerca de temáticas ${ }^{27}$ sobre a pesquisa e a pós-graduação em educação e ensino, tecidas por docentes da UFG, IFMT e UNIC, e sessóes de trabalhos em que os mestrandos apresentaram os seus projetos de pesquisa aos professores debatedores/avaliadores e ao público presente.

No quarto semestre, ocorrido de 08.04.2017 a 17.07.2017, os servidores mestrandos deram seguimento àquelas atividades, anteriormente elencadas, inerentes a esse processo e, dentre eles, três realizaram seus exames de qualificação no mês de maio e suas defesas públicas de dissertação no mês de agosto, finalizando, assim, o curso, no prazo regular de dois anos. Outros quatro, ainda, se qualificaram no mês de junho.

Considerando-se o prazo regulamentar de execução do Minter em vinte e quatro meses, conforme previsto no projeto, esse quarto semestre corresponderia ao último período do curso, no entanto, houve a necessidade de prolongá-lo por causa dos atrasos nos cronogramas das pesquisas da maioria dos servidores mestrandos, gerados por diversos motivos, dentre eles, o pouco tempo de redução de seus encargos profissionais para desenvolverem nele as suas pesquisas e a demora na expedição das análises, diligências e pareceres do Conselho de Ética em Pesquisa (CEP) da UFG e do IFMT.

Diante dessa situaçáo e, considerando que o projeto do Minter previa a realização de mais um semestre para atendimento desse tipo de demanda, o PPGE/FE/UFG, respaldado pelo seu regulamento, aprovou e homologou todos os requerimentos de prorrogação de prazos dos alunos solicitantes para fins de conclusão das suas pesquisas e da realização dos exames de qualificaçóes e defesas das dissertaçóes.

Por outro lado, as Coordenaçóes locais do Minter da UFG e IFMT elaboraram a minuta do termo aditivo do acordo firmado entre as duas instituiçôes parceiras, a qual foi aprovada por ambas dando origem ao $1^{\text {o }}$ Termo Aditivo do Minter, datado de 26.06.2017, que prorrogou o convênio interinstitucional e a vigência do curso para mais seis meses.

Assim, no quinto e último semestre, ocorrido de 21.08.2017 a 15.03.2018, os servidores mestrandos finalizaram as últimas fases da pesquisa, orientação e produção de texto para submissão à avaliação em exame de qualificação, sendo

27 Tema 1: Políticas para formação de professores; tema 2: Os fundamentos Pedagógicos da BNCC; tema 3: Conhecimento Especializado de Professores: possíveis impactos; e tema 4: Financiamento da educação. 
quatro em setembro, um em outubro, um em novembro e três em dezembro ${ }^{28}$, bem como para a defesa pública da dissertação, sendo um em outubro, um em novembro, dois em dezembro de 2017, sete em fevereiro e um em março de 2018.

\section{Financiamento do Minter em Educação PPGE/FE/UFG/IFMT}

A CAPES, no Edital n. 23/2014, definindo que os projetos Minters/Dinters submetidos seriam avaliados exclusivamente quanto ao mérito acadêmico, ficando, assim, dissociados de análise quanto aos aspectos de financiamento, não previu diretamente o apoio financeiro para a execução destes e, com isso, permitiu que os aprovados pudessem obter independentes e diferentes formas de financiamento ${ }^{29}$.

Sendo assim, após a aprovação do projeto na CAPES, o PPGE/FE/UFG formulou o Plano de Trabalho do Minter em Educação, no valor de R\$ 275.000,00 (duzentos e setenta e cinco mil reais), para sua implantação e submeteu-o à apreciaçáo do IFMT que, acatando-o e aprovando-o, elaborou, por intermédio da PROPES e da Pró-Reitoria de Administração (PROAD), o Plano de Aplicação Financeira referente. Este documento, denominado Termo de Execução Descentralizada (TED) n. 1, de 23 de março de 2016, definiu o repasse daquele recurso financeiro ao PPGE/FE/UFG para a execução física e orçamentária do curso.

Assim, tal montante, originário do orçamento do IFMT pelo Programa de Trabalho 2031 - Educação Profissional e Tecnológica, Programa 2109 - Programa de Gestão e Manutenção do Ministério da Educação e Ação 4572 - Capacitação de Servidores Públicos Federais em Processo de Qualificação e Requalificação, foi descentralizado à instituição promotora em três parcelas anuais ${ }^{30}$ para utilização nas seguintes rubricas: 339020 - auxílio financeiro a pesquisadores; 339039 outros serviços de terceiros/pessoa jurídica; 339033 - passagens e despesas com locomoção; 339014 - diárias/pessoal civil; 339036 - outros serviços de terceiros/ pessoa física; 339030 - material de consumo; e 449052 - equipamentos e material permanente, conforme previsto no Plano de Trabalho aprovado (IFMT, 2016).

28 Dentre esses, houve uma reprovação.

29 Recursos das próprias IES, de parcerias e de convênios com setores de outros ministérios, de editais da própria CAPES e das demais agências federais, de editais das Fundaçóes Estaduais de Amparo à Pesquisa, entre outros.

$301^{\text {a }}$ parcela de $\mathrm{R} \$ 118.700,00$ em 2016; $2^{\mathrm{a}}$ parcela de $\mathrm{R} \$ 65.500,00$ em 2017; e $3^{\mathrm{a}}$ parcela de $\mathrm{R} \$$ $90.800,00$ em 2018. 
Além desses recursos da instituição receptora, o Minter em Educação PPGE/FE/UFG/IFMT contou, também, com o apoio financeiro advindo do Governo Estadual que, por intermédio da sua Fundação de Amparo à Pesquisa do Estado de Mato Grosso (FAPEMAT) em parceria com a CAPES, lançou o Edital n. 003/2015, de 9 de fevereiro de 2015, para apoio a programas de mestrado e doutorado interinstitucional, recomendados pela CAPES, que beneficiassem IES sediadas no estado de Mato Grosso.

Diante dessa possibilidade de captar recursos financeiros para a execução do curso, a Coordenação local do Minter do IFMT, na condição de concessionária, elaborou e submeteu, em 3 de abril, o Projeto intitulado "Mestrado Interinstitucional em Educação - UFG/IFMT", que foi aprovado em 22 de setembro no valor de $\mathrm{R} \$ 165.670,00^{31}$ (cento e sessenta e cinco mil, seiscentos e setenta reais) para utilização nas rubricas 339014 - diárias, 39033 - passagens, 339030 - material de consumo e 339039 - Serviço de Terceiro (pessoa jurídica), conforme determinado no Termo de concessão e aceitação de auxílio (FAPEMAT, 2015).

Esses recursos financeiros ${ }^{32}$ possibilitaram um auxílio a todos os membros envolvidos no Minter (coordenadores, professores, orientadores e servidores mestrandos) no provento, no âmbito das rubricas aprovadas, de algumas despesas geradas na execução das suas atividades e das pesquisas durante as fases de desenvolvimento do curso.

Igualmente, oportunizou a divulgação dos resultados obtidos no Minter, em termos da produção do conhecimento, por meio do financiamento à confecção da coletânea de textos, na qual se insere este relato de experiência, referentes às dissertaçóes decorrentes das pesquisas empreendidas.

\section{Resultados e impacto do Minter em Educação PPGE/FE/UFG/IFMT}

Os frutos gerados no decorrer do itinerário coletivo de capacitação dos servidores do IFMT, sob o encargo da UFG, sinalizam que a experiência fez-se exitosa em sua realização, bem como em sua conclusão, em diversos aspectos.

Dos dezesseis iniciantes, quinze deles, sendo sete docentes e oito TAEs, concluíram integralmente o caminho formativo que lhes concedeu a titu-

31 O valor proposto no projeto submetido foi de $\mathrm{R} \$ 176.145,00$ (cento e setenta e seis mil, cento e quarenta e cinco reais), porém houve um corte de R \$ 10.475,00 (dez mil, quatrocentos e setenta e cinco reais).

32 Concedidos mediante Termo de concessão e aceitação de auxílio a projeto Minter/Dinter, Processo $\mathrm{n}^{\circ} .184833 / 2015$, foram disponibilizados em conta bancária somente em 23 de dezembro de 2015 . 
lação de Mestre(a) em Educação, ou seja, noventa e quatro por cento dos participantes finalizaram o processo.

Embora essa maioria não represente um número suficientemente expressivo de titulados em relação à demanda ainda persistente no IFMT, pode-se afirmar, já com um juízo avaliativo, que houve um acerto no estabelecimento da parceria interinstitucional para a execução da proveitosa inciativa, pois:

As avaliaçôes dos mestrados interinstitucionais não se definem tanto por números, por quantitativos, mas, sobretudo, pelas novas possibilidades que daí resultam para as políticas educacionais e de formação, e pelos processos de subjetivação emergentes em cada agenciamento concreto, em cada atualização específica, abrindo-se a novos/outros modos (est)éticos de existência social-política-cultural, de compreensão do ensinar-aprender, ou do conhecer-interpretar no âmbito dessa existência. (AXT, 2005, p. 6).

Nesse sentido, em termos qualitativos, o Minter em Educação oportunizou aos quinze profissionais da educação do Instituto um ambiente propício e rico de estímulos ao aprimoramento da formação profissional, à integração, interação e trocas de experiências com diversificados grupos de estudos e pesquisas, à apropriação de saberes, à mobilização para realizaçáo de investigaçóes científicas, à reelaboração e produção do conhecimento e, principalmente, às reflexóes acerca de diversas temáticas educacionais, especialmente, aquelas diretamente relacionadas as suas práticas profissionais, ao contexto institucional, local ou regional.

As respostas desses servidores, ante a essas oportunidades ofertadas e abraçadas, para além da obtenção do título, se revelaram na superação das dificuldades de toda ordem, no estabelecimento das relaçôes de sociabilidade e solidariedade, na iniciação à atividade científica, na construção da índole de pesquisador(a), na autorreflexão, no aprimoramento da formaçáo, em suma, nos avanços e conquistas pessoais que, certamente, irão influenciar todas as suas açóes, especialmente, as profissionais.

Assim, ainda que eles sejam um pequeno grupo no universo do quadro total de servidores do IFMT, terão condiçóes de atuar como agentes multiplicadores nos seus campi de vinculação, tal qual na instituição, no sentido de repensar a ação profissional, buscar solução e superação de problemas e 
demandas educacionais, contribuir com a melhoria e qualidade do ensino ofertado, propor e realizar pesquisas, fomentar a criaçáo de grupos de estudos e de pesquisas e contribuir com os já existentes, auxiliar na implantação de novos cursos de pós-graduação lato e stricto sensu e no fortalecimento dos atuais, enfim, de agir expressando o compromisso com a realidade educacional em que se inserem.

Longhi (2005, p. 40) enfatiza que "somente recursos humanos preparados, com qualificação científico-crítica inserida em suas realidades, é que poderão coordenar um processo de verdadeiro desenvolvimento humano sustentável”.

Por outro lado, em termos de produção científica na área, também estarão contribuindo por meio das dissertaçóes resultantes dos estudos e pesquisas que desenvolveram no universo acadêmico do Minter, cujos títulos seguem relacionados abaixo, por linha de pesquisa.

\section{LP I - Educação, Trabalho e Movimentos Sociais}

1. Contribuições da política de assistência estudantil na permanência/não permanência dos educandos do PROEJA do IFMT - Campus Várzea Grande. (Carminha Aparecida Visquetti)

2. (Re)pensando o PROEJA no IFMT - Campus Várzea Grande, a partir do olhar do(s) professor(es). (Sônia Maria de Almeida)

\section{LP II - Estado, Políticas e História da Educação}

3. A criação da Rede Federal de Educação Profissional, Científica e Tecnológica (RFEPCT) e a origem do Instituto Federal de Mato Grosso (IFMT). (Kátia Valéria Alves de Lima)

4. Introducção da sciencia no amago da instrucção primária: o ensino de ciências naturais no terceiro livro de leitura de Felisberto de Carvalho (1895-1959). (Edna Pereira dos Santos Ferreira)

5. O Curso Técnico em Estradas: das origens à implementação na Escola Técnica Federal de Mato Grosso. (Pedro José de Barros)

\section{LP III - Cultura e Processos Educacionais}

6. A formação do leitor na filmografia de Walter Salles. (Luiz Maria Dumont) 
7. Meio ambiente e educação: percepção ambiental de jovens alunos acerca da água (IFMT). (Adelson da Costa Ribeiro)

8. O pensamento de Merleau-Ponty na pintura contemporânea: reflexôes sobre o ensino da arte. (Reinaldo Gomes de Arruda)

\section{LP IV - Formação, Profissionalização Docente e Trabalho Educativo}

9. A formação do pensamento teórico na teoria do ensino desenvolvimental: contribuiçôes para o ensino de química. (Andréia Andreoli Silvestre)

10. A experimentação no ensino de biologia: contribuiçôes da teoria do ensino desenvolvimental. (Edna Souza de Almeida Miranda)

11. Perspectivas de formação integrada nos cursos técnicos do IFMT - Campus Rondonópolis. (Rudinei Itamar Tamiosso Wesz)

\section{LP V - Fundamentos dos Processos Educativos}

12. O Brasil moderno e a educação para o trabalho em Cuiabá: A Escola de Aprendizes Artífices de Mato Grosso (1909-1942). (Túlio Marcel Rufino de Vasconcelos Figueiredo)

13. Indústria cultural e pseudoformação: a racionalidade do desenho animado mais assistido no cinema. (Cristiano Costa Pereira)

14. Estudos sobre o ensino de teatro na escola e a apropriação da teoria crítica. (José Márcio Nerone Leite)

15. Aproximaçôes entre psicanálise e escrita de rua. (Rafael José Triches Nunes)

Esses trabalhos, conforme expressam seus títulos, tiveram seus focos de pesquisa voltados aos temas educacionais relacionados à realidade local, bem como revelam o compromisso assumido dos pesquisadores com o locus de trabalho e a preocupação em refletir sobre determinadas questóes neles presentes.

Para o IFMT, tais produçóes representam um benefício relevante, posto que traduzem a capacitação e a qualificação de membros do quadro de servidores que se tornam imprescindíveis ao desenvolvimento do ensino, pesquisa e extensão, e que reforçam o êxito da política institucional de formação continuada em nível da pós-graduação.

Outrossim, as produçóes apresentam análises científicas dos fenômenos do ambiente institucional educativo que podem subsidiar as tomadas de decisóes 
para a criação de grupos de pesquisa e cursos de pós-graduação na área de educação, bem como fundamentar a construção das políticas educacionais voltadas às necessidades locais e regionais, pois, conforme lembra Longhi (2005, p. 40), a instituição:

[...] receptora, respeitadas as devidas proporçóes, exerce uma liderança local/regional e tem função social na construção e distribuição de conhecimentos importantes ao desenvolvimento econômico, científico, tecnológico, social, cultural, humano das comunidades e região.

Para o PPGE/FE/UFG, os trabalhos produzidos refletem o cumprimento do acordo assumido de atuar na formação reflexiva de docentes e pesquisadores no IFMT e, consequentemente, no estado de Mato Grosso e na regiáo, também o compromisso de ampliar os conhecimentos e fortalecer a área da Educação, de oferecer instrumentos e bases teóricas para subsidiar as pesquisas dos servidores mestrandos, de fortalecer grupos e redes de pesquisa, de estabelecer parcerias duradouras com a receptora e, como afirmam Streck, Sudbrack e Zitkoski (2008, p. 130), de "fomentar uma atitude favorável à investigação, à inovação, à formação para toda a vida e em todas as carreiras profissionais".

O Programa, na execução desse Minter, explorou e expandiu seu potencial já consolidado na oferta da pós-graduação voltada à capacitação de docentes e de profissionais da educação, ofertando meios para a diminuição das disparidades educacionais do país, apostando na solidariedade entre instituições, diversificando, aprimorando e compartilhando experiências acumuladas para ampliação da base da pesquisa educacional no país.

Em termos finais e conclusivos, a realização desse investimento foi produtiva e positiva porque se baseou em parceria idônea, que respeitou as exigências legais, desde o planejamento, às fases constitutivas e conclusivas, constituindo-se numa convivência saudável, num cooperativismo institucional e num manancial de contínuas aprendizagens. 


\section{REFERÊNCIAS}

AXT, Margarete. Mestrado interinstitucional: entre o macropolítico e o micropolítico. In: JANTSCH, Ari Paulo; ERN, Edel; BIANCHETTI, Lucídio; DAROS, Maria das Dores (Orgs.). Mestrado em Educação: Experiências Interinstitucionais na Região Sul. Lages: Editora UNIPLAC, 2005. p. 5-7.

FUNDAÇÃO DE AMPARO À PESQUISA DO ESTADO DE MATO GROSSO (FAPEMAT). Termo de concessáo e aceitaçáo de auxílio à projeto minter/dinter Edital FAPEMAT n. 003-2015, processo n. 184833/2015. Cuiabá: FAPEMAT, 2015. 7 p.

INSTITUTO FEDERAL DE EDUCAÇÃO, CIÊNCIA E TECNOLOGIA DE MATO GROSSO (IFMT). Plano de Desenvolvimento Institucional (PDI). Cuiabá: IFMT, 2009. 119 p.

. Termo de Execuçáo Descentralizada (TED) n. 1, de 23 de março de 2016. Cuiabá: IFMT, 2016. 6 p.

KUNZE, Nádia Cuiabano et al. Memórias da pós-graduação no IFMT/Campus Cuiabá. Cuiabá: IFMT, 2013. 48 p. Relatório Final de Projeto de Pesquisa de Iniciação Científica.

LONGHI, Solange Maria. Da exigência legal à estratégia das parcerias: a experiência dos mestrados interinstitucionais na UPF. In: JANTSCH, Ari Paulo; ERN, Edel; BIANCHETTI, Lucídio; DAROS, Maria das Dores (Orgs.). Mestrado em Educação: Experiências Interinstitucionais na Região Sul. Lages: Editora UNIPLAC, 2005. p. 29-44.

STRECK, Danilo Romeu; SUDBRACK, Edite Maria; ZITKOSKI, Jaime José. Produção acadêmica e impacto social: o potencial inovador e transformador de um mestrado interinstitucional (Minter). RBPG, Brasília, v. 5, n. 9, p. 126-145, dez. 2008.

UNIVERSIDADE FEDERAL DE GOIÁS (UFG); INSTITUTO FEDERAL DE EDUCAÇÃO, CIÊNCIA E TECNOLOGIA DE MATO GROSSO (IFMT). Projeto de Mestrado Interinstitucional em Educaçáo. Goiânia; Cuiabá: UFG; IFMT, 2014.

UNIVERSIDADE FEDERAL DE GOIÁS (UFG). Faculdade de Educação. Edital n. 02/2015. Edital de inscrição, seleção e matrícula do Curso de Mestrado Interinstitucional do Programa de Pós-Graduação em Educação da Faculdade de Educação da UFG oferecido aos docentes e técnicos administrativos em educação do IFMT. Goiânia: UFG, 2015.

. Pró-Reitoria de Administração e Finanças. Plano de Trabalho Minter UFG-IFMT. Goiânia: UFG, 2016. 6 p. 